\title{
Functions Accounting at the Enterprises of Dairy Cattle Breeding in the Context of Cost Pool According to Physiological Groups
}

Klychova G.S.

Kazan Federal University, Institute of Management, Economics and Finance, Kazan, 420008, Russia

Iskhakov A.T.

Kazan State Agrarian University, Kazan, 420015, Russia

Valieva G.R.

Kazan State Agrarian University, Kazan, 420015, Russia

Klychova A.S.

Kazan State Agrarian University, Kazan, 420015, Russia

Email:kgaukgs@mail.ru

\section{Doi:10.5901/mjss.2014.v5n24p98}

Abstract

The given article is devoted to accounting functions and development of the device for cost-pricing of milk and animal yield in dairy cattle breeding on the background of cost pool according to physiological groups that makes possible to find more exact cost values, to currently detail both actual and scheduled information and take managerial decisions on eliminating the effect of the distortions exposed and implement measures aimed at costs budgeting for a period ahead.

Keywords: dairy cattle breeding, physiological groups, managerial accounting, cost calculation, direct costs.

\section{Introduction}

Livestock producers noticed that the dry cows within various periods after not-milking milk and consume feeding-stuffs with different degree of intensity. In dairy cattle breeding it brought to such technology as cows housing with a glance to their physiological groups. As distinguished from mixed housing this technology makes possible to specialize milk cows' diet, improve the quality and enlarge the volume of the milk received.

\section{Theory}

The core of physiological groups technology lies in the fact that a milking herd is divided according to three criteria: the number of days post calving (D), daily lactation performance $(U)$ and scored by five-grade scale (K). Let us take the table of criteria for a milking herd division recommended by the federal state unitary enterprise (FGUP) "GVTS Minselkhoz of Russia (RF Ministry of Agriculture)".

Table 1. Criteria "D", "U", "K" for a milking herd division into groups

\begin{tabular}{|c|c|c|c|}
\hline Group number & Number of days post calving (D) & Daily lactation performance per head (U), $\mathrm{kg}$. & Body condition (K), grades \\
\hline 1 & $0-100$ & More than 24 & $3,5-2,5$ \\
\hline 2 & $101-200$ & $24-16$ & $2,5-3,0$ \\
\hline 3 & $201-305$ & $16-8$ & $3,0-3,75$ \\
\hline 4 & $306-345$ & - & $3,0-3,75$ \\
\hline 5 & $346-365$ & - & $3,0-3,75$ \\
\hline
\end{tabular}


The figures for daily lactation performance $(U)$ are taken on the assumption that annual milch cow productivity is equal to $6000 \mathrm{~kg}$. Let us characterize the given groups:

1) The first cow group called «the group of increasing the milk yield» is defined by the largest lactation performance: more than $24 \mathrm{~kg}$ per head in a day. The cows come to this group on the $6^{\text {th }}$ day after calving in a weakened state. High lactation performance of this group inevitably results in milking cows' weight reduction and even well-balanced diet cannot replenish the loss of energy. That is why the main goal of the cow management in the first physiological group (apart from milk yield) is cow's special care;

2) The second group is distinct by less lactation performance: (24-16 kg per head in a day). Within this period the cows begin to take weight since the reduction of lactation performance also brings to the diminishment of metabolic cost. The main goal of the cow management in this group is the prevention of decrease of daily lactation performance in more than $9 \%$ per month.

3) The third group is characterized by the least lactation performance (at most $16 \mathrm{~kg}$ of milk per cow in a day). As well as for the second group the main aim of the cow management in this group is the prevention of decrease of daily lactation performance in more than $9 \%$ per month. Here such objectives as thrush preventative, weight take -up and preparation to calving are realized;

4) The fourth group comprises dry cows. The period of not-milking lasts on average about 60 days, nearly 40 of which fall on this group. The aim of the cows housing in this group is the prevention of the cow's fetus overgrowth that can be the result of the excessive fleshing and lead to hard and complicated calving. The cow's diet should be balanced with micronutrients, magnesium, in particular, and contain minimal quantity of concentrated feeding stuff;

5) The fifth group is maternity barn. The cows stay there about 20 days before calving and 5 days after - to feed the yield by colostral milk. The cow begins to get the first group's diet within 20 days before calving. The mass of combined feed is gradually enlarged up to 3-4 kg per day. The cow management in this group is aimed at animal yield when calving takes place without outside help.

With a view to milk getting technology cows' management in physiological groups as compared to mixed housing promotes lactation performance, bettering of the health condition, production of healthy animal yield, concentrated feeding stuff saving within not-milking period, etc. With regard to financial and managerial accounting cows' management in physiological groups must imply costs record-keeping and cost accounting according to each group individually, when doing so, the main object of accounting in the first three groups will be a centner of milk produced but in $4^{\text {th }}$ and $5^{\text {th }}$ groups - animal yield. Various housing conditions in different groups and variants of diet are the most expensive items for the enterprises of dairy cattle breeding because it implies getting not the same self-cost of a centner of milk in a group. Prime costs should be also allocated either with a view to physiological groups or passing this stage - between final objects of accounting. Thus, in our opinion, the technology of a milking herd cost accounting should come along with the described above technology of separate cows' housing.

\section{Results}

The tool of assigning costs being direct in relation to physiological groups between such items as milk and animal yield is founded on the following proposed coefficients (Table 1)

Table 2. Coefficients of assigning costs being direct in relation to physiological groups between such items as milk and animal yield

\begin{tabular}{|c|c|c|c|c|c|}
\hline \multirow{2}{*}{ Objects of accounting } & \multicolumn{5}{|c|}{ Physiological groups } \\
\cline { 2 - 6 } & I group & II group & III group & IV group & V group \\
\hline Milk & 0,96 & 0,9 & 0,9 & 0 & 0 \\
\hline Animal yield & 0,04 & 0,1 & 0,1 & 1 & 1 \\
\hline
\end{tabular}

Since the cows are transferred to the first group on the $6^{\text {th }}$ day after calving, on the $65^{\text {th }}$ day they are conceived and on the $100^{\text {th }}$ day they come to the second group, in our opinion, it is necessary to take into account temporal factor and apply the proportion of not $90 \%$ to $10 \%$, but $96 \%$ to $4 \%$, i.e. the costs for animal yield are cut by more than twice. The temporal factor also implies that the conventional ratio of $90 \%$ to $10 \%$ should be used in the second and third physiological group where the cows have already become conceived. Consequently, metabolizable energy of the feeding stuff is consumed in size of $10 \%$ for yield from the first and up to the last day of the cows' stay in these groups. As for the cows being housed 
in the fourth and fifth groups, they are dry and, hence, their diet is completely gone in fetal development, i.e. 100\% of direct expenses are allocated for animal yield.

In the development of cows' management accounting by physiological groups it is necessary to consider the aspects of accounting direct and allocating indirect expenses of the enterprise which includes the conditions of milk and yield total and direct cost forming. With this end in view it is needed to state and describe input matrix of expenses for a milking herd management in physiological groups (Table 2).

Table 3. Input matrix of expenses for a milking herd management in physiological groups

\begin{tabular}{|c|c|c|c|c|c|c|}
\hline \multirow{2}{*}{ Divisions (TsO) } & \multicolumn{4}{|c|}{ Expenses for cows housing in physiological groups (FG) } & \multirow{2}{*}{ Total by TsO } \\
\cline { 2 - 6 } & $\Phi \Gamma_{1}$ & $\Phi \Gamma_{2}$ & $\Phi \Gamma_{3}$ & $\Phi \Gamma_{4}$ & $\Phi \Gamma_{5}$ & \\
\hline $\mathrm{TsO}_{1}$ & $\sum_{1,1}$ & $\sum_{1,2}$ & $\sum_{1,3}$ & $\sum_{1,4}$ & $\sum_{1,5}$ & $\sum_{1,2}$ \\
\hline $\mathrm{TsO}_{2}$ & $\sum_{2,1}$ & $\sum_{2,2}$ & $\sum_{2,3}$ & $\sum_{2,4}$ & $\sum_{2,5}$ & $\sum_{2, \mathrm{z}}$ \\
\hline$\ldots$ & $\ldots$ & $\ldots$ & $\ldots$ & $\ldots$ & $\ldots$ & $\ldots$ \\
\hline $\mathrm{TsO}_{\mathrm{n}}$ & $\sum_{\mathrm{n}, 1}$ & $\sum_{\mathrm{n}, 2}$ & $\sum_{\mathrm{n}, 3}$ & $\sum_{\mathrm{n}, 4}$ & $\sum_{\mathrm{n}, 5}$ & $\sum_{\mathrm{n}, \mathrm{z}}$ \\
\hline Total by FG at the enterprise & $\sum_{\mathrm{i}, 1}$ & $\sum_{\mathrm{i}, 2}$ & $\sum_{\mathrm{i}, 3}$ & $\sum_{\mathrm{i}, 4}$ & $\sum_{\mathrm{i}, 5}$ & $\begin{array}{c}\sum_{\mathrm{i}, \mathrm{i}} \\
(\mathrm{i}=1 \ldots \mathrm{n}) \\
(\mathrm{z}=1 \ldots . .5)\end{array}$ \\
\hline
\end{tabular}

As it is shown in the Table 2 in the course of accounting according to physiological group method accountants in managerial bookkeeping department will have possibility to enter expenses by two directions: in horizontal direction, i.e. each division individually, and in vertical - by each physiological group where the horizontal format is designated, primarily, for making decisions by the managers of the divisions and vertical format - for the operating efficiency analysis at the level of top management. In both cases direct expenses for cow management will be accounted on a mandatory basis. As for indirect costs, in this case there are variants available.

The most logically true at applying horizontal format, according to our reckoning, is the approach implying inclusion of general production expenses and general running costs into function costing that will make the managers of the certain level possible to take decisions in the field of pricing, cost optimization and their short payback period, etc. For vertical format it is logical to account only direct expenses. It is determined by the fact that in order to match the results of the goals stated before the subdivisions top management is needed a cost index free of expenses being not connected with the activities of the certain physiological group of the certain subdivision.

If the senior management is given a possibility to group both direct and indirect costs for cow housing with a view to vertical format of accounting, it will result in the situation when these subdivisions' workers can be able to vary the figures of indirect expenses allowed for costs group, for instance, by means of applying another allocation base, etc. This will probably mean the distortion of the accounting results and profitability ratio. To prevent this from happening, the senior management must develop tough instrument of expenses accounting and cost determination the same for all divisions in order to reconcile all the data stated in the accounts. However, allowing for the fact that the structure and method of indirect costs allocation should be provided in all inner company regulations and be corrected by totals of the accounting period. The approach of «tough regulation instrument» leads to the appearance of cost-based bureaucratic system that will result in the struggle for extra financial resources laid in the company budget instead of production growth and healthy competition arising.

\section{Conclusion}

In this connection it is more coherent to refuse from indirect costs accounting for housing of cows in groups and calculate the cost only by the indices of direct expenses as it was originally stipulated by «direct-cost method» developed by Jonathan Harris in 1936. Hence, the necessity of indirect cost tough regulation is eliminated, in any case, with a view to prediction of basic analytical indices presented below, in Table 3 , in relation to cows housing in physiological groups. It is noteworthy that waiver to include indirect costs in the analysis of core indicators automatically brings to one more problem related to the senior managers' temptation of transferring part of direct expenses into direct costs structure. In doing so they try to make possible «improving» baseline indices of effectiveness what is not positive for an enterprise as a whole. To solve this problem it is possible:

1) To elaborate the list and device for cost accounting by direct expenses the same for all divisions in order to reconcile all the data stated in the accounts. Similar to the case of full inclusion of expenses in the structure of 
cost it will be necessary to reconsider the scope of direct expenses by totals of the accounting period at the senior management level. So, on this side the danger of creating a bureaucratic system of regulation again springs up. The difference, however, lies in the fact that the scope of regulation proposed will be more modest since indirect expenses to be not taken into account and, hence, the whole system will be more flexible and viable.

Table 4. Performance indicators in relation to the tasks of the cows housing within physiological groups

\begin{tabular}{|c|c|c|}
\hline \multirow[t]{2}{*}{ Physiological groups } & \multicolumn{2}{|r|}{ Cows housing } \\
\hline & Technology goals & Performance indicators \\
\hline 1 & 2 & 3 \\
\hline $\begin{array}{l}1 \text { group - the group of } \\
\text { increasing the milk yield } \\
\text { (from } 0 \text { up to } 100 \text { days } \\
\text { after calving) }\end{array}$ & $\begin{array}{l}\text { Milk production, special cows care after } \\
\text { calving }\end{array}$ & $\begin{array}{l}\text { 1. Search of the group profitability ratio in each subdivision; } \\
\text { 2. The group profitability ratio correlation with the analogous } \\
\text { indicators in other subdivisions; } \\
\text { 3. Each group profitability ratio correlation with the analogous } \\
\text { indicators of the accounting period; } \\
\text { 4. Search of the group profitability ratio in a company as a } \\
\text { whole; } \\
\text { 5. The group profitability ratio correlation with the analogous } \\
\text { indicators of the accounting period in a company as a whole. }\end{array}$ \\
\hline $\begin{array}{l}2 \text { group } \\
\text { (101-200 days after } \\
\text { calving) }\end{array}$ & $\begin{array}{l}\text { Prevention of decrease of daily lactation } \\
\text { performance in more than } 9 \% \text { per } \\
\text { month. }\end{array}$ & $\begin{array}{l}\text { 1. Search of the group profitability ratio in each subdivision and } \\
\text { their correlation with the analogous indicators of the previous } \\
\text { months ; } \\
\text { 2. The group profitability ratio correlation with the analogous }\end{array}$ \\
\hline $\begin{array}{l}3 \text { group } \\
\text { (201-305 days after } \\
\text { calving) }\end{array}$ & $\begin{array}{l}\text { Prevention of decrease of daily lactation } \\
\text { performance in more than } 9 \% \text { per } \\
\text { month. }\end{array}$ & $\begin{array}{l}\text { indicators in other subdivisions; } \\
\text { 3. Search of the group profitability ratio in a company as a } \\
\text { whole and their correlation with the analogous indicators of the } \\
\text { previous months. }\end{array}$ \\
\hline $\begin{array}{l}4 \text { group } \\
\text { (306-345 days after } \\
\text { calving) }\end{array}$ & Cow preparation to successful calving & $\begin{array}{l}\text { 1. Search of calf crop actual costs per head in each } \\
\text { subdivision; } \\
\text { 2. Correlation of cost figures found with the scheduled ones in } \\
\text { each subdivision; }\end{array}$ \\
\hline $\begin{array}{l}5 \text { group } \\
\text { (346-365 days after } \\
\text { calving) }\end{array}$ & Animal yield production & $\begin{array}{l}\text { 3. Correlation of calf crop actual costs in a subdivision with the } \\
\text { analogous indicators in other subdivisions; } \\
\text { 4. Search of calf crop actual costs per head in a company as a } \\
\text { whole and their correlation with the analogous scheduled } \\
\text { indicators. }\end{array}$ \\
\hline
\end{tabular}

2) Since, indirect cost pool takes place in horizontal format of expenses accounting the idea of parallel monitoring indirect items dynamics especially in relation to scheduled figures and including the data of the previous periods, results of correlation with other subdivisions' analogous indicators, etc. seems to be logical. Each of the given above paragraphs ( 1 and 2 ) can be applied individually.

The cow housing performance indicators are not limited by those stated in Table 3 but, however, it appears to be the main list for the assessment of fulfilling tasks related to cow management pursuant to physiological groups. So, the performance indicators of the first physiological group do not imply juxtaposition of different physiological groups' profit margin with the analogous data of the previous months, as, for instance, the first group or «the group of increasing the milk yield» is defined by the largest figures of milk yield. The peak of the milk yield falls to $40^{\text {th }}-50^{\text {th }}$ day further the figures begin to slightly decline but remain to stay at rather a high level. Therefore, at this stage the main goal is not so much monitor the dynamics of monthly milk yield decline as getting the more milk yield and, consequently, maximal book rate of return, be meant, without compromising the procedures of cow care after calving. Nevertheless, the performance indicators for the first group assume juxtaposition of the obtained results with the analogous data of the previous accounting periods, not per month but quarterly and annual profit margin values.

The index of effectiveness in the $2^{\text {nd }}$ and $3^{d}$ groups can be calculated separately from each other in view of the fact that the preset (scheduled) values of milk yield for the $2^{\text {nd }}$ group will be higher than for the $3^{\mathrm{d}}$ one, as these groups' milch cow productivity falls by the intrinsic (physiological) reasons. However, the objectives for the technology of cow housing in these groups coincide and from this perspective the indexes of effectiveness in the reports of various subdivisions can be united, therewithal, the task of this groups' milk yield dynamics monitoring per month comes to the fore. Respectively 
analytical accounting of costs for cows housing should be made according to the months of cows staying in groups.

It should be noted, that the search of the enterprisewide indices of milk yield profit margin is characteristic for all the groups that makes the senior management possible to estimate the enterprise produce competitiveness on a consumer market, to soften the processes of pricing formation, and, vice versa, to use pan-corporate product sale price as a guide for the price calculation. When doing so, in order to find profitability ratio in separate groups it becomes possible to use milk yield index-numbers as sales volume accounting on the basis of quantities correlated for pancorporate product sale price.

The last two groups are interrelated by a single goal - bovine offspring. In this light it is not necessary to search cow management expenditure level in $4^{\text {th }}$ and $5^{\text {th }}$ groups separately. The expenditures for both groups are one way or another laid in cost per cow yield head, therewith, care should be taken to the fact that fodder costs for 1-3 groups are allocated between milk and animal yield by means of the ratios stated in Table 5 .

As can be seen from the above, at calculating cost per cow yield head apart from the $4^{\text {th }}$ and fifth groups' own expenditures it is necessary to add secondary costs of the previous groups. Consequently, to find profitability index for 13 groups we use solely the costs related to milk yield but not to animal yield in the following ratios $96 \%$ to $4 \%$ and $90 \%$ to $10 \%$, appropriately. Schematically it can be shown in the following way (Fig.1).

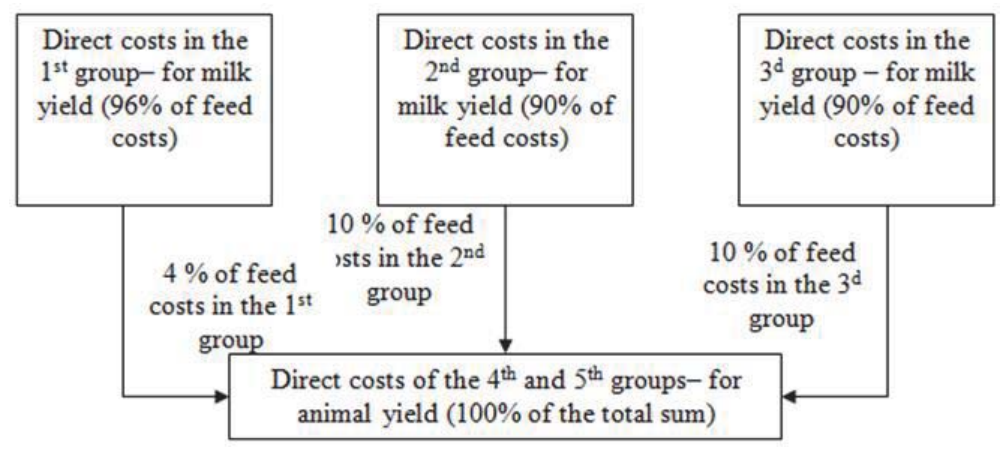

Fig.1. Allocation of feed costs for finding performance indicators for cow housing in physiological groups

In order to make a company-wide analysis the senior managers of a dairy cattle breeding enterprise can calculate selfcost of animal yield per head in all subdivisions. Provided that the activities of the separate subdivisions are relatively identical, a company-wide self-cost can be used in forming a target price per head with a view to enter the calves into accounting records within a year.

At analyzing the scheme given above and the performance indicators from Table 3 inference should be drawn that some convention exists in cost pooling between the $2^{\text {nd }}$ and $3^{\text {d }}$ groups as well as the $4^{\text {th }}$ and the $5^{\text {th }}$. In other words, it could be possible not to regard all 5 physiological groups of animal housing but take into accounting only the $1^{\text {st }}, 2^{\text {nd }}, 3^{\mathrm{d}}$ and $4^{\text {th }}$ ones where the costs of the $4^{\text {th }}$ and the $5^{\text {th }}$ groups are combined. Moreover, the costs of groups 2 and 3 can be also combined with the result that only three groups of animal housing account are left what will significantly facilitate the enterprise managerial staff's work. At the same time, it should be noted that availability of three groups instead of five though simplifies these groups' performance measurements analysis but is not possible to objectively estimate milk yield self-cost at each stage of cow housing technology use. Milk yield self-cost received according to the $2^{\text {nd }}$ and $3^{\mathrm{d}}$ groups remains to be different and combining these groups' indices will subsequently bring to cost figures distortion and, hence, to the distortion of the main point in the accounting by physiological groups.

The same relates to groups 4 and 5: despite their interrelation they are not at all identical. The housing of the cows in the $4^{\text {th }}$ group is aimed at their preparation to calving. Correspondingly, while pooling the costs within the determined framework the medium-level managers prepare and submit to the management the information about the charges for a 45 -days' preparatory phase before calving not only for each subdivision but for the whole enterprise. As for the costs combined into the fifth group, called a maternity barn, they reflect information of the calving cost. Thus, the convention of groups division into the $4^{\text {th }}$ and the $5^{\text {th }}$ lies not in the fact that both groups are associated with the animal yield birth but is related to the matter of what time will be required for a cow transferred from the $4^{\text {th }}$ group into the $5^{\text {th }}$ to give birth to a calf - a week, a couple of weeks or days.

As it has been already mentioned, to estimate overall subdivision performance horizontal format is used which is based on explicitation of costs in relation to each physiological group. At the same time, combining groups within the 
frames of horizontal format makes no sense since it is implemented only with a view to more fast performance measurements analysis, especially in relation to tasks intrinsic to the technology of cows housing in physiological groups (Table 3) and to compiling accounts for the senior management. But as far as the subdivisions are concerned, they do need information about the groups to make managerial decisions of costs optimization. So, the cows housed in the $4^{\text {th }}$ group receive a limited diet rich in mineral additives while the cows of the fifth «maternity» group are gradually transferred to the group of increasing the milk yield's diet. It can be explicable on the basis of the fact that a cow's fetus will not give an excessive growth within some days left before the calving, at the same time, microbial population in the rumen will be prepared for the lactation period. Therefore, separate accounting in groups four and five will make possible within the whole accounting period to monitor any change associated with cows' management and influencing their performance and well-being. By the totals of the accounting period the heads of the subdivisions can take managerial decisions on eliminating the effect of the distortions exposed and implement measures aimed at costs budgeting for a period ahead. In what connection the procedures of costs accounting according to physiological groups are simplified since cows transfer from one group to another is mapped out to the last day and each physiological group has a certain costs structure and distinctive performance data.

\section{References}

Klychova G.S., Iskhakov A.T. Solar batteries use in agriculture and energy accounting // Mediterranean Journal of Social Science. 2014. - № 12. -pp. 187-191.

Klychova G.S. Costs accounting enhancement and production costs calculation at agricultural enterprises / G.S. Klychova, A.R. Zakirova // Economy of agricultural undertakings and processing companies. - 2003. - № 3. - pp. 30-31.

Klychova G.S. Managerial (production process) accounting in agriculture / G.S. Klychova, E. R. Sadrieva, A.R. Zakirova - Kazan: Kazan University Publishing House, 2006. - 288 p.

Methodological recommendations on book records of production expenditures and production costs (works and services) calculation at agricultural undertakings, Order of Minselkhoz of Russia (RF Ministry of Agriculture) dated June, 6, 2003. № 792. - On-line legal documentation service «Guarantor».

Ivashkevich V.P. Management accounting: college textbook. - M.: Economist, 2004.- 618 p.

Petrov E. B., Taratorkin V.M. Critical process parameters of state-of-the-art technology of milk production at the enterprises of animal husbandry (farms)/ E. B. Petrov, V.M. Taratorkin. - Methodical guidelines. - M.: FGNU «Rosinformagrotech», 2007. - 176 p.

Klychova G.S., Features calculation of production of fur farming/ Klychova G.S., Zakirova A.R., Klychova A.S.// Bulletin of Kazan State Agrarian University. - 2012. - № 3 (25), P. 20-26.

Horngren Ch. T., Foster J. Accounting: administrative aspect: trans. from English. / Ed. Ya.V.Sokolova. Moscow: Finance and Statistics, 2000. - 576 p. (in Russian)

Scone T. Managerial Accounting: How it should be used to control business: Translated from English under the editorship of Eriashvili. M.: Audit, UNITI, 1997. - $179 \mathrm{p}$.

Horngren Ch. T., Foster J. Book Records: management accounting aspect/ Translated from English under the editorship of Ya. V. Sokolov. - M.: Finance and Statistics, 2000 - 576 p. 